Boise State University

ScholarWorks

7-1-2012

Shorter Migration Distances Associated with Higher Winter Temperatures Suggest a Mechanism for Advancing Nesting Phenology of American Kestrels Falco sparverius

Julie A. Heath

Boise State University

Karen Steenhof

Owyhee Desert Studies

Mark A. Foster

Boise State University 


\title{
Shorter Migration Distances Associated with Higher Winter Temperatures Suggest a Mechanism for Advancing Nesting Phenology of American Kestrels
}

\author{
Julie A. Heath \\ Boise State University \\ Karen Steenhof \\ Owyhee Desert Studies \\ Mark A. Foster \\ Boise State University
}

\begin{abstract}
Global climate change has affected avian migration patterns and nesting phenology. Changes in one phase of a bird's cycle will most likely affect other stages, but few studies focus simultaneously on multiple life-history events. We used western North American ringing records and Christmas Bird Counts to examine whether changes in migration patterns were concordant with advancing American kestrel (Falco sparverius) nesting phenology. Consistent with previous findings, male kestrels migrated shorter distances than female kestrels, and kestrels nesting in southern latitudes migrated shorter distances than kestrels nesting in more northern areas. In addition, kestrel migration distance decreased significantly from 1960-2009 and was negatively associated with winter minimum temperatures. Christmas Birds Counts from the same time period showed increasing indices of overwintering kestrel abundance in northern states (Washington, Idaho, and Utah), where winter minimum temperatures have increased significantly, and concomitant decreases in southern states (California and Arizona). Finally, changes in nesting phenology of kestrels in southwestern Idaho were best explained by warmer winters, not springs. Warmer winters may decrease energetic demands on migrants by allowing for shorter migration distances, decreasing thermoregulatory costs, or both. Decreased energy demands during winter may allow birds to gain resources necessary for reproduction earlier in the nesting season. Higher winter temperatures that decrease (former) constraints on early nesting may be a particularly important mechanism leading to advancing nesting phenology for species with strong seasonal declines in fecundity or intense early season competition for high-quality nesting areas.
\end{abstract}

Keywords: band, climate change, overwinter, reproduction, short-stopping

Climate change has been associated with changes in avian life history patterns. Changes in one life-history event are likely to affect other aspects of an annual cycle, and climate change may have variable impacts on life histories depending on the role of climate in driving life history patterns (Both and Visser 2001, Visser et al. 2003, Both and Visser 2005, Gordo et al. 2005, Balbontín et al. 2009, Lehikoinen et al. 2010, Smallegange et al. 2010). Interactions among climate and life history events may be especially complex for migratory birds that experience variation in the type and magnitude of climate change across seasons and locations (Balbontín et al. 2009). Several migratory species show decreased migration distances (Berthold et al. 1992, Fiedler et al. 2004, Visser et al. 2009, Smallegange et al. 2010), shifting over-wintering distributions (Zuckerberg et al. 2011), or a complete cessation of migratory behavior (van Vliet et al. 2009) in areas with warmer winters. Decreased costs associated with shorter migration distances, decreased thermoregulatory demands, increased winter food availability (Romanowski and Żmihorski 2009), or a combination of these changes, may affect nesting phenology by facilitating obtainment of energetic resources necessary for reproduction or allowing for early return to nesting areas (Przybylo et al. 2000, Nooker et al. 2005).

Birds that nest earlier in the season typically have higher reproductive success compared to conspecifics that nest later in the season (Perrins 1970, Newton 1979), and high competition for quality nest sites and mates often results in only a few individuals producing most of the juveniles that survive to recruitment (Espie et al. 2000, Grande et al. 
2009). Given a strong seasonal decline in reproductive success, and the heritability of nesting phenology (van Noordwijk et al. 1981, van der Jeugd and McCleery 2002), one might predict that nesting seasons would advance over time (Gienapp and Visser 2006). For birds that depend on resource availability at the time of egg production (i.e., income breeders), severe winter and early spring conditions may constrain directional change in nesting phenology (Meijer et al. 1999, Nooker et al. 2005, Drent et al. 2006, Gienapp and Visser 2006). Climate change may release prior ecological constraints on early nesting by decreasing costs associated with over-wintering near nesting areas, facilitating earlier attainment of reproductive condition, or both. Once the energetic constraints related to winter severity have decreased, the underlying relationship between early nesting and reproductive success may drive rapid advancement of nesting seasons.

The American kestrel (Falco sparverius) is a widely distributed, cavity-nesting falcon that feeds on a variety of prey including insects, small mammals, reptiles, and birds. American kestrels in southwestern Idaho are nesting approximately 21 days earlier than they did 20 years ago (Steenhof and Peterson 2009a). In this population, early nesting pairs are more likely to produce young (Strasser 2010), and these young are more likely to survive and return to the nesting population compared to young produced by later nesters (Steenhof and Heath, in review). In addition, adult female kestrels that nest early in the season have higher survival and return rates, independent of success, compared to adult females that nest later in the season (Steenhof and Heath 2009). In central and eastern North America, evidence from both migration watchsites (Farmer and Smith 2009) and breeding populations (Smallwood et al. 2009) suggest that American kestrels are experiencing a population decline. In western North America, the numbers of migrating American kestrels observed at some watchsites have decreased significantly from 1995-2005 (Farmer and Smith 2009). However, to date, there is no evidence that kestrel nesting populations are decreasing in western states (Steenhof and Peterson 2009a). The decrease in migrating kestrels at western watchsites may indicate that western kestrels are declining, fewer kestrels are migrating, or both.

We hypothesize that climate change has affected western kestrel migratory behaviour and, as a result, some kestrels may show earlier nest initiation. Specifically, birds are migrating shorter distances and overwintering further north because the thermoregulatory and energetic constraints of remaining near nesting areas have decreased with climate change. The strong seasonal decline in reproductive success and apparent survival drive earlier nest initiation. In this paper, we use ringing records to evaluate whether migration distances of American kestrels in western North America have changed from 1960-2010. We also evaluate changes in overwintering American kestrel populations in the western U.S. using data from the National Audubon Society's 1960-2009 Christmas Bird Counts (CBC). Finally, we examine the relationship between advancing nesting dates and local weather conditions for kestrels nesting in southwestern Idaho. We explore whether shifts in nesting were associated with winter or spring weather conditions.

\section{Methods}

\section{Study species}

American kestrels show a variety of migration strategies. Kestrels from northern populations tend to have a higher proportion of migrants compared to southern populations (Henny 1972, Bird and Palmer 1988), and males migrate shorter distances than females (Willoughby and Cade 1964). American kestrels are strong north-south migrants and use distinct migration flyways between nesting and wintering areas, especially in western North America (Henny and Brady 1994, Hoffman et al. 2002). Southward migration begins in mid-Aug; by the last week in Oct the southernmost watch sites in New Mexico have counted $>90 \%$ of their total kestrel observations (Smith and Neal 2009). The timing of southward migration may be limited by completion of a post-nesting molt, which may cause adults to migrate later than juveniles (Smallwood and Bird 2002). Kestrels defend winter territories and earlyarriving birds occupy higher quality overwintering sites than late-arriving birds (Smallwood and Bird 2002). Northward migration begins in early Mar and most kestrels arrive on their nesting grounds by 1 Apr (Henny 1972), although nesting may begin earlier at southern sites (Smallwood and Bird 2002). The migration study area boundaries were the Pacific Ocean in the west and the Rocky Mountains in the east. Ringing records included birds nesting as far north as British Columbia, Canada and wintering as far south as Hidalgo, Mexico. No kestrels ringed within this area were encountered east of the Rocky Mountains. 


\section{Migration distance}

We used ringing and encounter records of American kestrels kept by the North American Bird Banding Program (BBL), a program that is jointly administered by the United States Department of the Interior and the Canadian Wildlife Service, to investigate changes in migration distance. Data were limited to kestrels ringed near nesting areas during the spring and summer (1 Apr -15 Aug) and encountered on wintering areas (1 Nov - $28 \mathrm{Feb})$ or kestrels ringed on wintering areas $(1 \mathrm{Nov}-28 \mathrm{Feb})$ and encountered during the spring and summer $(1 \mathrm{Apr}-15$ Aug). Winter seasons were labeled by the Nov-Dec year of each winter.

No records were missing information about ringing date or location, and records lacking information about encounter date or locations were removed. Birds that were recovered as skeleton only, birds reared by hand, or held in captivity for $>24 \mathrm{hrs}$ when ringed also were removed. The BBL required that ringing and encounter locations be reported to the nearest $10^{\prime}$ block of latitude or longitude. Kestrels encountered in the same 10' block where the kestrel was ringed $(n=33)$ were excluded because these records may be the result of increased ringer efforts to obtain encounters (Fiedler et al. 2004), and birds overwintering within nesting areas may be distinctly different than migrants (Visser et al. 2009). Records of marked kestrels encountered by ringers in a different 10' block from where they were originally ringed $(n=9)$ were not removed. Records before 1960 were omitted because encounters were sparse before this year $(n=5)$. The final dataset consisted of 104 encounters from 1960-2009 with 61\% afterhatch year birds, 32\% hatch-year birds, $7 \%$ unknown age birds. The distance between ringing and encounter locations was calculated along a loxodromic path (constant direction bearing) (Fiedler et al. 2004, Visser et al. 2009).

Some kestrels $(46 \%)$ were encountered $>270 \mathrm{~d}$ after ringing. A bird's nesting area was assumed to be the same location where it was originally ringed or, for birds marked in the winter, later encountered. Although birds may disperse between nesting seasons, kestrel dispersal distances tend to be relatively short $\left(<13 \mathrm{~km}\right.$, or within a $10^{\text {' }}$ block) compared to migration movements (Smallwood and Bird 2002, Steenhof and Peterson 2009b). Further, there were no significant residual patterns from a regression of migration distance and number of days between ringing and encounter date to suggest that dispersal may have biased the results.

\section{Overwintering areas}

Christmas Bird Count data for western states (Washington, Oregon, California, Idaho, Utah, Nevada, Arizona) were queried from the National Audubon website (National Audubon Society 2010). Christmas Bird Counts were conducted by volunteers who counted all birds detected within a designated survey area of one 24-km diameter circle, on 1 day between 14 Dec and 5 Jan (National Audubon Society 2010). American kestrels occur in areas likely to be surveyed by volunteers and are relatively easy to detect and identify because of their size and use of exposed perches (Fuller and Mosher 1981). The number of kestrels per 100 observer hours (kestrels_100hr ${ }^{-1}$ ) was used as an index of wintering populations within each state (Kim et al. 2008). Analysis was limited to CBC's conducted from 1960-2009 to be consistent with the ringing data and because kestrels were not regularly reported in each state's CBC until 1960 (some states did not have counts every year pre-1960).

\section{Nesting phenology}

From 1987 to 2009, except for 2007, a population of American kestrels nesting in boxes in southwestern Idaho was monitored ( $43^{\circ} \mathrm{N} 116^{\circ} \mathrm{W}$; Steenhof and Heath 2009). Each year, prior to the nesting season, nest boxes were cleaned and lined with pine shavings. Beginning in early March, boxes were visited every 7-21 days to determine occupancy and clutch size. Nest discovery dates (dates when fresh eggs were first found) were used as an index of nest initiation because occasionally nests were discovered with complete clutches (Steenhof and Heath 2009). Nest discovery dates correlated well with hatching dates $(r=0.89, n=577, p<0.001)$ and were considered to be a reliable index of nest initiation.

\section{Climate variables}

We selected large-scale and landscape-scale temperature data based on evidence from other studies that both largescale (Kim et al. 2008) and landscape-scale (Visser et al. 2009) weather patterns may predict migration or phenology changes. Large-scale climate patterns were represented by the southern oscillation index (SOI) (Kiladis and Diaz 
1989). Warmer winters (El Niño) are associated with negative SOI values and cooler winters (La Niña) are associated with positive SOI values (Kiladis and Diaz 1989). SOI data were accessed from the National Oceanic and Atmospheric Administration Climate Prediction Center (http://www.cpc.ncep.noaa.gov/data/indices/soi) and monthly SOI values (Nov-Feb) were averaged for each winter from 1960-2009.

Landscape-level climate patterns were represented by minimum air temperature anomaly data from the Global Historical Climatology Network gridded dataset (HadGHCND, http://www.ncdc.noaa.gov/oa/climate/ghcn-daily/). The grid dataset provides daily minimum temperature anomalies compiled for several climate stations within a grid $\left(2.5^{\circ}\right.$ latitude by $3.75^{\circ}$ longitude) area. Daily anomalies were the difference of each daily minimum temperature from a daily "base" value (Caesar et al. 2006). Daily "base" minimum temperatures were calculated for each climate station's minimum temperature records from 1961-1990 using a five-day window centered on each day (Caesar et al. 2006). The use of anomaly values, versus recorded temperatures, allowed for standardized representation of climate change across a variety of locations with different minimum temperatures. We averaged daily minimum temperature anomalies for each winter (Nov-Feb) 1960-2009 for all western North America grids. We used "spatial join" in ArcGIS (ESRI 2009) to associate individual kestrel nesting locations with the closest grid station in the HadGHCND dataset and then queried the average daily minimum temperature anomaly for the winter the kestrel was encountered, or ringed as a wintering bird. We also averaged the daily minimum temperatures during winter across each state from 1990-2009 to index the amount of change in each state's daily minimum temperatures. Finally, we used daily minimum temperature anomaly data from the HadGHCND station nearest the southwestern Idaho kestrel population to examine changes in winter and spring minimum temperatures from 19872009. Spring months were defined as Mar and Apr to coincide with the months when migratory birds arrive from overwintering areas and initiate nesting (Crick and Sparks 1999; Both et al. 2010).

\section{Statistics}

We used a linear model with migration distance as the dependent variable, and sex, SOI, nesting latitude, winter (winter that the bird was encountered or initially ringed), age, and minimum winter temperature anomaly for the nesting site in the winter of encounter (or ringing) as predictor variables to understand the factors associated with kestrel migration distance. Terms for interactions between sex and winter, minimum temperature anomaly, and SOI, and interactions between nesting latitude with winter, minimum temperature anomaly, and SOI also were included. Nesting latitude, SOI, minimum temperature anomaly, and winter were standardized by subtracting the mean from each observation and dividing by the standard error of the variable to allow for effect sizes to be more easily compared (Rhodes et al. 2009). The natural log of the loxodromic distance between ringing and encounter locations to represent migration distance was used to meet assumptions of randomly distributed residuals. Multicollinearity $(|r|>0.7)$ among our predictor variables was checked with a correlation analysis. Terms from the full model were removed in a stepwise fashion when $\mathrm{p}>0.05$. Parameter estimates were based on the final model.

We removed two outliers from the CBC data before analysis (California $\mathrm{n}=1$, Oregon $\mathrm{n}=1$ ). Annual kestrel_100 $\mathrm{hr}^{-1}$ outliers were more than 1.5 standard deviations than average kestrel_100hr ${ }^{-1}$ in the two years preceding and after the outlier year. We used analysis of covariance to examine whether year, state or the interaction between year and state best explained kestrels_100 $\mathrm{hr}^{-1}$. There was a significant interaction between year and state so we used state-specific linear models with the independent variable of winter predicting the dependent variable kestrels_100 $\mathrm{hr}^{-1}$ to examine temporal trends in overwintering kestrels. We examined changes in each state's winter weather using a one-sample t-test of the null hypothesis that mean winter minimum temperature anomalies from 1990-2009 have not changed $(\mu=0)$ with respect to the base period of 1961-1990.

We used a linear model to examine whether the dependent variable of average American kestrel nest discovery dates changed over the study period, 1987-2009. Linear models also were used to understand whether winter minimum temperature anomalies or spring minimum temperature anomalies changed over the same time period. We examined the associations between average date of nest discovery and average daily minimum temperature anomalies from winter and spring with linear models where average date of nest discovery was the dependent variable and temperature anomaly was the independent variable. Analyses were performed in SAS 9.2 (SAS Institute Inc. 2008) or R 2.12.1 (R Development Core Team 2009) 


\section{Results}

\section{Migration distance}

American kestrel migration distance depended on sex, nesting latitude, winter minimum temperature anomalies, and winter-year (Table 1). Female kestrels migrated farther than male kestrels (Table 1). Kestrels nesting in more northern latitudes migrated farther than kestrels nesting in more southern latitudes (Table 1). Kestrels migrated farther during colder winters than warmer winters (Table 1), and kestrel migration distances decreased significantly over time (Fig. 1). Trends of decreasing migration distances over time did not depend on sex or nesting latitude (all interactions $\mathrm{p}>0.05)$. Large-scale weather patterns, specifically the SOI $\left(\mathrm{F}_{1,98}=0.05, \mathrm{p}=0.66\right)$, and age $\left(\mathrm{F}_{1,97}=\right.$ $0.08, \mathrm{p}=0.78)$ were not predictive of migration distances. Twenty-one birds (20\% of 104) in the final dataset consisted of birds ringed or encountered in southwesten Idaho during the nesting season.

Changes in migration distances may result from spatial shifts in ringing effort or encounter probability over time (Visser et al. 2009). Specifically, shorter migration distances in winters could result from increased sampling of short distance migrants (males or birds from southern latitudes) in recent years. We examined whether sampling bias could explain temporal trends in migration distances by testing for temporal trends in the sex or nesting latitude composition of our ring encounter sample. The proportion of males and females did not change over time (generalized linear model with logit link, Wald $X^{2}=2.1, \mathrm{p}=0.15$ ). Nesting latitude and winter year correlated positively $\left(r_{s}=0.25, p=0.01\right.$ ), suggesting that more northern nesting birds were sampled in recent winters. If migration distances were not changing over time, this correlation should produce a temporal trend of increasing migration distances, because northern kestrels migrate farther than kestrels nesting in southern latitudes. Therefore, sampling bias is unlikely to be driving the temporal trend of decreasing migration distance observed in the final model.

\section{Overwintering areas}

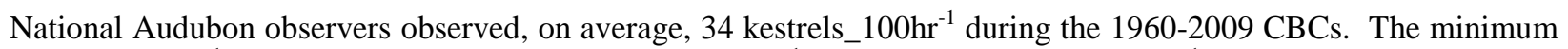
kestrels_100hr ${ }^{-1}$ was 0.8 and the maximum kestrels_ $100 \mathrm{hr}^{-1}$ was 86 . The kestrels_ $100 \mathrm{hr}^{-1}$ changed significantly over time, and patterns of change depended on state (year*state interaction, $\mathrm{F}_{6,333}=28.14, \mathrm{p}<0.0001$ ). Kestrels_100hr ${ }^{-1}$ increased significantly from 1960-2009 for Washington $(\beta=0.38 \pm 0.04$, CI: $0.29-0.47)$, Idaho $(\beta=0.50 \pm 0.13$, CI: $0.23-0.76)$, and Utah $(\beta=0.67 \pm 0.07$, CI: $0.5-0.82)$. In contrast, kestrels_100hr ${ }^{-1}$ decreased significantly over the past 40 years in California $(\beta=-0.66 \pm 0.09$, CI: $-0.83--0.47)$ and Arizona $(\beta=-0.31 \pm 0.06$, CI: $-0.44--0.18)$. Kestrels_100hr ${ }^{-1}$ did not change significantly over time for CBCs in Oregon $(\beta=-0.14 \pm 0.09$, CI: $-0.30-0.05)$ and Nevada $(\beta=0 \pm 0$, CI: $-0.2-0.2)$ (Fig. 2). Despite these trends California consistently recorded the highest kestrels_100hr ${ }^{-1}(58 \pm 1.2)$ compared to Idaho $(45 \pm 1.2)$, Oregon $(41 \pm 1.2)$, Utah (31 \pm 1.2$)$, Arizona $(27 \pm 1.2)$, Nevada (26 \pm 1.2$)$, and Washington ( $15 \pm 1.2)$, in decreasing order.

One possible alternative explanation for declining trends in kestrels_ $100 \mathrm{hr}^{-1}$ is that observer groups in recent years spent more time in areas that were not suitable wintering habitat for kestrels. The number of CBC observer hours increased for all states but the proportion of counts in California and Arizona reporting kestrels did not change, suggesting that there were not a disproportionate number of new counts in unsuitable habitat.

During the years of 1990-2009, winter minimum temperatures increased in several western states relative to the 1961-1990 reference period used to calculate minimum temperature anomalies. Minimum winter temperature anomalies from 1990-2009 for Washington $\left(\mathrm{t}_{(1) 19}=2.89, \mathrm{p}=0.009\right)$, Idaho $\left(\mathrm{t}_{(1) 19}=2.11, \mathrm{p}=0.048\right)$, Utah $\left(\mathrm{t}_{(1) 19}=\right.$ 2.73, $\mathrm{P}=0.013)$, California $\left(\mathrm{t}_{(1) 19}=2.63, \mathrm{p}=0.016\right)$, and Arizona $\left(\mathrm{t}_{(1) 19}=4.83, \mathrm{p}=0.0002\right)$ were all significantly greater than zero (Fig. 2a). Over the same time period, winter minimum temperature anomalies for Oregon $\left(\mathrm{t}_{(1) 19}=\right.$ $1.70, \mathrm{p}=0.105)$ and Nevada $\left(\mathrm{t}_{(1) 19}=1.99, \mathrm{p}=0.06\right)$ did not differ significantly from zero (Fig. 2a). Northern states with an increase in winter minimum temperature anomalies (Washington, Idaho, and Utah) all had increasing kestrels_100 $\mathrm{hr}^{-1}$ while southern states with an increase in winter minimum temperature (California and Arizona) had decreasing kestrels_100 $\mathrm{hr}^{-1}$. The two states lacking a change in winter temperature anomalies over time (Oregon and Nevada) had no trends kestrels_100hr ${ }^{-1}$ (Fig. 2). 


\section{Nesting phenology}

We documented nest discovery dates for 999 American kestrel nesting attempts in southwestern Idaho from 1987 2009 except 2007. Nest discovery dates ranged from 26 March to 9 July, and average nest discovery date has advanced significantly over the past 22 years $\left(\beta=-1.4 \pm 0.1, \mathrm{CI}:-1.7--1.1, \mathrm{~F}_{1,20}=63.72, \mathrm{p}<0.0001\right)$. Average minimum temperature anomalies during winter months (Nov-Feb) in southwestern Idaho have increased significantly over that same time period $\left(\beta=0.08 \pm 0.04\right.$, CI: $\left.0.01-0.16, \mathrm{~F}_{1,21}=4.83, \mathrm{p}=0.039\right)$. Average minimum temperature anomalies during spring have not changed significantly $(\beta=-0.04 \pm 0.02$, CI: $-0.09-0.003$, $\left.\mathrm{F}_{1,21}=3.02, \mathrm{p}=0.097\right)$ and winter and spring anomalies were not correlated with each other $(\mathrm{r}=-0.06, \mathrm{p}=0.79)$. Annual mean nest discovery dates were associated with minimum temperature anomalies during the winter $\left(\mathrm{F}_{1,20}=\right.$ $6.68, p=0.018$, Fig. 3), but not with average minimum temperature anomalies during spring $\left(\mathrm{F}_{1,20}=2.46, \mathrm{p}=0.13\right)$. Kestrels tended to nest earlier in seasons preceded by a warmer winter $(\beta=-3.9 \pm 1.4, \mathrm{CI}:-6.7--1.1)$.

\section{Discussion}

Our analyses of 49 years of ring encounter data for American kestrels western North America documented two strong patterns of differential migration that have been shown previously: females migrate greater distances than males, and kestrels nesting at northern latitudes migrate greater distances than kestrels nesting at southern latitudes (Willoughby and Cade 1964, Smallwood and Bird 2002). After controlling for these two patterns, we found that kestrel migration distances in western North America have decreased significantly between 1960 and 2009. We also found that kestrels migrated shorter distances when winter minimum temperatures were warmer on their nesting grounds. A decrease in American kestrel migration distances in response to increasing winter temperatures is consistent with findings from Visser et al. (2009) and Smallegange et al. (2010) that have shown evidence for decreased migration distances for many European bird species.

Changes in migration distance corresponded with our analysis of $\mathrm{CBC}$ data collected during the same period. CBCs showed increasing trends in overwintering kestrels in northern states, where winter minimum temperatures have increased in recent years, and decreasing trends in overwintering kestrels in southern states. We would predict declining counts in southern states if northern kestrels were migrating shorter distances and wintering at more northern latitudes. These results were consistent with climate change studies that have shown pole-ward shifts in wintering grounds (La Sorte and Thompson 2007). Many environmental conditions may affect kestrel migration distances and wintering distributions, such as increased risk or energetic costs because of stop-over and winter habitat degradation or loss. In this case, poor conditions on wintering grounds and decreased costs associated with wintering near nesting areas because of increased temperatures may have an additive effect in driving shorter migration distances and more northern winter distributions. In a time of global change, understanding the relative effect sizes of land-use and climate will be important.

Kestrels in southwestern Idaho have advanced their clutch initiation by almost a month since 1987. For many species, changes in nesting phenology have been explained primarily by the hypothesis that warmer springs and earlier growing seasons drive advancement of prey availability (i.e., insect emergence) and birds ultimately benefit by arriving early to nesting areas and timing their reproduction to coincide with periods of high food availability (van Noordwijk et al. 1995, Crick et al. 1997, Dunn and Winkler 1999, Strode 2003, Both et al. 2004, Both and Visser 2005, Bradshaw and Holzapfel 2006, Smallegange et al. 2010). The effect of shifts in prey availability relative to other selection pressures, such as early attainment of reproductive condition and competition for quality nest sites, may be less important for a generalist species that forages on a variety of prey with asynchronous abundance patterns (Both et al. 2010) or heterogeneous distributions (Jonzén et al. 2007). Changes in growing seasons or prey availability may affect kestrel nesting phenology; however, spring temperatures in Idaho have not changed over the past 20 years and nesting phenology shifts were not associated with spring temperatures. Kestrel nest discovery dates were associated with higher winter minimum temperature anomalies suggesting that changes in winter ecology (i.e., increased over-wintering near the breeding grounds) allowed for advancing kestrel nesting phenology. Further, generalizing from regional patterns of shorter migration distances and northern increases in wintering populations to the Idaho population seems reasonable because $20 \%$ of the ringing data consisted of birds nesting in southwestern Idaho and there were significant increases in the number of kestrels counted during the Idaho CBC. It is likely that kestrels in southwestern Idaho migrate shorter distances in response to warmer winters. If cues about prey availability were advancing, kestrels wintering near nesting areas may be better able to respond to 
prey phenology shifts (Butler 2003, Lehikoinen et al. 2004, Végvári et al. 2010). Understanding the relative effects of changes in the growing season and changes in the winter season will be an important area for future research.

In southwestern Idaho, early nesting is associated with increased reproductive success and production of offspring that are more likely to survive and recruit to the local population (Strasser 2010, Steenhof and Heath, in review). Early nesting barn swallows (Hirundo rustica) (Møller 2008) and great tits (Parus major) (Verboven and Visser 1998) also produce more local recruits compared to later nesting conspecifics. For species with high early-season fecundity, we suggest that warmer winters could be driving recent shifts towards early clutch initiation by releasing constraints that previously limited early nesting.

Warming winters may be conducive to shorter migration distances and overwintering at more northern latitudes because of decreased thermoregulatory costs, increased prey availability in winter months (Romanowski and Żmihorski 2009), or both. Shorter migration distances and minimization of energetic demands may result in females arriving at nesting areas in better condition. Experimental evidence has shown that a strong proximal constraint on laying dates is the inability of the female to find sufficient nutrients (Drent et al. 2006). This mechanism is supported by evidence from Mexican jays (Aphelocoma ultramarine, Brown et al. 1999), tree swallows (Tachycineta bicolor; Nooker et al. 2005), collared flycatchers (Ficedula albicollis, Przybylo et al. 2000), common eiders (Somateria mollissima, D’Alba et al. 2010), and golden eagles (Aquila chrysaetos, Steenhof et al. 1997). These studies show shifts towards earlier nesting when energetic costs were reduced during warmer winters. European starlings (Sturnus vulgaris) delayed reproduction in a study that experimentally increased female thermoregulation costs by decreasing nest box temperatures (Meijer et al. 1999). Similarly, if warmer winters also have decreased snow cover (as is true in Idaho), increased foraging opportunities for wintering kestrels may lead to earlier attainment of reproductive condition, which could allow birds to advance their nesting activity.

A rapid selection for decreasing migration distance and earlier nesting may be explained by potential fitness gains conferred by these behaviours across the full annual cycle (Bearhop et al. 2005, Pulido and Berthold 2010). Early nesting allows for a longer pre-migratory period for juvenile birds, allowing juveniles more time to gain foraging experience prior to their first migration, which may increase survival of juveniles to recruitment or, in some areas, allow juveniles to establish territories for subsequent nesting seasons (Smallwood and Smallwood 1998). Adults that finish nesting earlier may be able to complete their molt earlier, allowing migrant adults to depart earlier for overwintering areas. Kestrels that arrive on wintering areas earlier gain higher quality territories compared to kestrels that arrive later (Smallwood 1988). Similarly, adults that migrate shorter distances or not at all may establish winter territories near nesting areas (Steenhof and Heath, unpubl. data). Early arriving males may be able to secure access to high quality nesting territories and early arriving females may benefit from access to high-quality males. Unfortunately, we do not have long-term data to evaluate shifts in the timing of first arrival dates for kestrels in southwestern Idaho. However, this pattern is supported by evidence from prairie falcons (Falco mexicanus) overwintering on their nesting grounds in southwestern Idaho that began nesting 2-3 weeks earlier than longdistance migrants; early nesting prairie falcons had higher nesting success rates than later nesting migrants (Steenhof et al. 2005). In raptors, access to quality mates and territories is an important predictor of lifetime reproductive success (Newton 1979, Espie et al. 2000) and likely to be a strong selection pressure favoring early attainment of reproduction condition.

Studies of avian life cycles in changing climates can offer interesting insights to evolutionary patterns and ecological constraints. Further, understanding the mechanisms by which climate change affects phenology, distributions, and behaviour is important for species conservation because monitoring and management programs require informed predictions about population responses. For example, most song birds are monitored during the breeding season by auditory point counts that depend on detection of bird songs, and raptors are monitored at migration watchsites. As phenology and migration patterns change, the availability of individual birds for detection during surveys may also change, making it difficult to determine if trends in population indices represent changes in population size or shifts in life history patterns (McClure et al. 2011). Declining counts of American kestrels at western migration watchsites may indicate a decrease in kestrel populations, changes in migration patterns, or both. We suggest that warming winters may release prior ecological constraints on early nesting by allowing shorter migration distances or earlier attainment of reproductive condition. Whether these migration pattern and phenology shifts result in changes in overall population sizes remains uncertain. Incorporation of changes in life history events and the associated carryover effects will be an important component of population monitoring and management in a time of climate change. 


\section{Acknowledgements}

We thank kestrel ringers, the BBL, and National Audubon Society volunteers for conducting Christmas Bird Counts. Field procedures followed Animal Care Protocol guidelines approved by Boise State University (IACUC Numbers 006-01-006, 006-05-004, and 06-08-007). This project was supported by Boise State University, the Raptor Research Center, North American Bluebird Society, the Society for Integrative and Comparative Biology, Boise State University's Provost Office undergraduate research work study funds, and the NSF Idaho EPSCoR Program (EPS-0814387). Funding for data collection from 1987 to 2005 was provided mainly by the Boise District Bureau of Land Management, the National Biological Survey, and the U.S. Geological Survey, Forest and Rangeland Ecosystem Science Center, Snake River Field Station. We appreciate the Idaho land owners that allowed us to access kestrel boxes on their property. We thank L. Dunn, C. Hayes, E. Strasser, T. Patel and B. Peterson for help in the field. Comments from C. Lott, T. Piersma, and 2 anonymous reviewers improved earlier drafts of this manuscript. 


\section{References}

Balbontín, J., Møller, A.P., Hermosell, I.G., Marzal, A., Reviriego, M. and De Lope, F. 2009. Individual responses in spring arrival date to ecological conditions during winter and migration in a migratory bird.- J. Anim. Ecol. 78: 981-989.

Bearhop, S., Fiedler, W., Furness, R.W., Votier, S.C., Waldron, S., Newton, J., Bowen, G.J., Berthold, P. and Farnsworth, K. 2005 Assortative mating as a mechanism for rapid evolution of a migratory divide.Science 310: 502-504.

Berthold, P., Helbig, A.J., Mohr, G. and Querner, U. 1992 Rapid microevolution of migratory behavior in a wild bird species.- Nature 360: 668-670.

Bird, D.M., and Palmer, R.S. 1988. American kestrel. Handbook of North American birds Vol. 5: diurnal raptors (ed. Palmer, R. S.), pp. 253-290. Yale University Press, New Haven, Connecticut, USA.

Both, C. and Visser, M.E. 2001. Adjustment to climate change is constrained by arrival date in a long-distance migrant bird.- Nature 411: 296-298.

Both, C. and Visser, M.E. 2005. The effect of climate change on the correlation between avian life-history traits.Global Change Biol. 11: 1606-1613.

Both, C., Artemyev, A.V., Blaauw, B., Cowie, R.J., Dekhuijzen, A.J., Eeva,T., Enemar, A., Gustafsson, L., Ivankina, E.V., Järvinen, A., Metcalfe, N.B., Nyholm, N.E.I., Potti, J., Ravussin, P.-A., Sanz, J.J., Silverin, B. Slater, F.M., Sokolov, L.V., Török, J., Winkel, W., Wright, J., Zang, H. and Visser, M.E. 2004. Largescale geographical variation confirms that climate change causes birds to lay earlier.- Proc. R. Soc. B 271: 1657-1662.

Both, C., Van Turnhout, C.A.M., Bijlsma, R.G., Siepel, H., Van Strien, A.J. and Foppen, R.P.B. 2010. Avian population consequences of climate change are most severe for long-distance migrants in seasonal habitats.Proc. R. Soc. B 277: 1259-1266.

Bradshaw, W.E. and Holzapfel, C.M. 2006. Climate change-evolutionary response to rapid climate change.Science 312: 1477-1478.

Brown, J.L., Li, S.H. and Bhagabati, N. 1999. Long-term trend toward earlier breeding in an American bird: a response to global warming?- Proc. Natl. Acad. Sci. USA 96: 5565-5569.

Butler, C.J. 2003. The disproportionate effect of global warming on the arrival dates of short-distance migratory birds in North America.- Ibis 145: 484-495.

Caesar, J., Alexander, L. and Vose, R. 2006. Large-scale changes in observed daily maximum and minimum temperatures: creation and analysis of a new gridded data set.- J. Geophys. Res. 111, (DOI 10.1029/2005JD006280)

Crick, H.Q.P., Dudley, C., Glue, D.E. and Thomson, D.L. 1997. UK birds are laying eggs earlier.- Nature 388: 526-526.

Crick, H.Q.P. and Sparks, T.H. 1999. Climate change related to egg-laying trends.- Nature 399: 423-424.

D'Alba, L., Monaghan P. and Nager R.G. 2010. Advances in laying date and increasing population size suggest positive responses to climate change in common eiders Somateria mollissima in Iceland.- Ibis 152: 19-28.

Drent, R.J., Fox, A.D. and Stahl J. 2006. Travelling to breed.- J. Ornithol. 147: 122-134.

Dunn, P.O. and Winkler, D.W. 1999. Climate change has affected the breeding date of tree swallows throughout North America.- Proc. R. Soc. B 266: 2487-2490.

Environmental Systems Resource Institute 2009. ArcMap 9.2. ESRI, Redlands, California, USA.

Espie, R.H.M., Oliphant, L.W., James, P.C., Warkentin, I.G. and Lieske, D.J. 2000. Age-dependent breeding performance in merlins (Falco columbarius).- Ecology 81: 3404-3415.

Farmer, C.J., and Smith, J.P.. 2009. Migration monitoring indicates widespread declines of American Kestrels (Falco sparverius) in North America. J. Rapt. Res. 43:263-273.

Fiedler, W., Bairlein, F. and Köppen, U. 2004. Using large-scale data from ringed birds for the investigation of effects of climate change on migrating birds: pitfalls and prospects.- Adv. Ecol. Res. 35: 49-67.

Fuller, M.R., and Mosher, J.A. 1981. Methods of detecting and counting raptors: a review.- Studies in Avian Biology 6: 235-246.

Gienapp, P. and Visser, M.E. 2006. Possible fitness consequences of experimentally advanced laying dates in great tits: differences between populations in different habitats.- Funct. Ecol. 20: 180-185.

Gordo, O., Brotons, L., Ferrer, X. and Comas, P. 2005. Do changes in climate patterns in wintering areas affect the timing of the spring arrival of trans-Saharan migrant birds?- Global Change Biol. 11: 12-21. 
Grande, J.M., Serrano, D., Tavecchia, G., Carrete, M., Ceballos, O., Díaz-Delgado, R. Tella, J.L. and Donázar, J.A. 2009. Survival in a long-lived territorial migrant: effects of life-history traits and ecological conditions in wintering and breeding areas.- Oikos 118: 580-590.

Henny, C.J. 1972. An analysis of the population dynamics of selected avian species. United State Fish and Wildlife Service Research Report 1, United States Government Printing Office, Washington D. C., USA.

Henny, C.J. and Brady, G.L. 1994. Partial migration and wintering localities of American kestrels nesting in the Pacific Northwest.- Northwest. Nat. 75: 37-43.

Hoffman, S.W., Smith, J.P., and Meehan, T.D. 2002. Breeding grounds, winter ranges, and migratory routes of raptors in the mountain west.- J. Raptor Res. 36: 97-110.

van der Jeugd, H.P. and McCleery, R. 2002. Effects of spatial autocorrelation, natal philopatry and phenotypic plasticity on the heritability of laying date.- J. Evol. Biol. 15: 380-387.

Jonzén, N., Hedenstrom, A. and Lundberg, P. 2007. Climate change and the optimal arrival of migratory birds.Proc. R. Soc. B 274: 269-274.

Kiladis, G.N., and Diaz, H.F. 1989. Global climatic anomalies associated with extremes in the Southern Oscillation.- J. Climate 2: 1069-1090.

Kim, D.H., Slack, R.D. and Chavez-Ramirez, F. 2008. Impacts of El Niño-Southern Oscillation events on the distribution of wintering raptors.- J. Wildl. Manage. 72: 231-239.

La Sorte, F.A. and Thompson, F.R. 2007. Poleward shifts in winter ranges of North American birds.- Ecology 88: 1803-1812.

Lehikoinen, A., Saurola, P., Byholm, P., Lindén, A., and Valkama, J. 2010. Life history events of the Eurasian sparrowhawk Accipiter nisus in a changing climate.- J. Avian Biol. 41: 627-636.

Lehikoinen, E., Sparks T.H., and Zalakevicius M. 2004. Arrival and departure dates. Advances in Ecological Research, Birds and Climate Change (eds. Møller, A.P., Fiedler, W. and Berthold, P.) 35: 1-31.

McClure, C.J.W., Burkett-Cadena, N.D., Ligon, R.A., and Hill, G.E. 2011. Actual or perceived abundance? Interpreting annual survey data in the face of changing phenologies.- Condor 113: 490-500.

Meijer, T., Nienaber, U., Langer, U. and Trillmich, F. 1999. Temperature and timing of egg-laying of European starlings.- Condor 101: 124-132.

Møller, A. 2008. Climate change and micro-geographic variation in laying date.- Oecologia 155: 845-857.

National Audubon Society. 2010. The Christmas Bird Count historical results [Online]. Available http://www.christmasbirdcount.org [1 Mar 2011]

Newton, I. 1979. Population Ecology of Raptors. T. and A .D. Poyser Ltd., Berkhamsted, England.

Nooker, J.K., Dunn, P.O. and Whittingham, L.A. 2005. Effects of food abundance, weather, and female condition on reproduction in tree swallows (Tachycineta bicolor).- Auk 122: 1225-1238.

van Noordwijk, A.J., van Balen, J.H. and Scharloo, W. 1981. Genetic variation in the timing of reproduction in the great tit.- Oecologia 49: 158-166.

van Noordwijk, A.J., McCleery, R.H. and Perrins, C.M. 1995. Selection for the timing of great tit breeding in relation to caterpillar growth and temperature.- J. Anim. Ecol. 64: 451-458.

Perrins, C.M. 1970. The timing of bird's breeding seasons.- Ibis 112: 242-255.

Przybylo, R., Sheldon, B.C. and Merilä, J. 2000. Climatic effects on breeding and morphology: evidence for phenotypic plasticity.- J. Anim. Ecol. 69: 395-403.

Pulido, F. and Berthold, P. 2010. Current selection for lower migratory activity will drive the evolution of residency in a migratory bird population.- Proc. Natl. Acad. Sci. USA 107: 7341-7346.

R Development Core Team 2009. R: A Language and Environment for Statistical Computing. R Foundation for Statistical Computing, Vienna, Austria.

Rhodes, J. R., C. A. McAlpine, A. F. Zuur, G. M. Smith, and E. N. Ieno. 2009. GLMM applied on the spatial distribution of koalas in a fragmented landscape, p. 469-492. In A. F. Zuur, E. N. Ieno, N. J. Walker, A. A. Savaliev and G. M. Smith [eds.], Mixed effects models and extensions in ecology in R. Springer, New York.

Romanowski, J. and Żmihorski, M. 2009. Seasonal and habitat variation in the diet of the tawny owl (Strix aluco) in Central Poland during unusually warm years.- Biologia 64: 365-369.

SAS Institute. 2008. SAS 9.2, Cary, North Carolina, USA.

Smallegange, I.M., Fiedler, W., Köppen, U., Geiter, O. and Bairlein, F. 2010. Tits on the move: exploring the impact of environmental change on blue tit and great tit migration distance.- J. Anim. Ecol. 79: 350-357.

Smallwood, J.A. 1988. A mechanism of sexual segregation by habitat in American kestrels (Falco sparverius) wintering in southcentral Florida.- Auk 105: 36-46. 
Smallwood, J. A., M. F. Causey, M. F., Mossop, D. H., Klucsarits, J.R., Robertson, B. Robertson, S., Mason, J., Maurer, M. J., Melvin, R. J., Dawson, R. D., Bortolotti, G.R., Parrish, J.W., Breen, T.F., and Boyd, K. 2009. Why are American kestrel (Falco sparverius) populations declining in North America? Evidence from nest-box programs. J. Rapt. Res. 43: 274-282.

Smallwood, J.A., and Bird, D.M. 2002. American kestrel (Falco sparverius). The Birds of North America (ed. Poole, A.). Cornell Lab of Ornithology, Ithaca, New York, USA, Available: http://bna.birds.cornell.edu/bna/species/602.

Smallwood, P.D. and Smallwood, J.A. 1998. Seasonal shifts in sex ratios of fledgling American kestrels (Falco sparverius paulus); the early bird hypothesis.- Evol. Ecol. 12: 839-853.

Smith, J.P., and Neal, M.C. 2009. Fall 2009 raptor migration studies in the Manzano Mountains of central New Mexico. HawkWatch International, Inc., Salt Lake City, Utah, USA.

Steenhof, K., Fuller, M.R., Kochert, M.N., and Bates, K.K. 2005. Long-range movements and breeding dispersal of prairie falcons from southwest Idaho.- Condor 107: 481-496.

Steenhof, K. and Heath, J.A. In review. Local recruitment, natal dispersal distances, and inbreeding in American kestrels.- Condor.

Steenhof, K. and Heath, J.A. 2009. American kestrel reproduction: evidence for the selection hypothesis and the role of dispersal.- Ibis 151: 493-501.

Steenhof, K., Kochert, M.N. and McDonald, T.L. 1997. Interactive effects of prey and weather on Golden Eagle reproduction.- J. Anim. Ecol. 66: 350-362.

Steenhof, K. and Peterson, B.E. 2009a. American kestrel reproduction in southwestern Idaho: annual variation and long-term trends.- J. Raptor Res. 43: 283-290.

Steenhof, K. and Peterson, B.E. 2009b. Site fidelity, mate fidelity, and breeding dispersal in American kestrels.Wilson J. Ornith. 121: 12-21.

Strasser, E.H. 2010. Reproductive failure and the stress response in American kestrels nesting along a human disturbance gradient. MS Thesis. Boise State University, Boise, ID.

Strode, P.K. 2003. Implications of climate change for North American wood warblers (Parulidae).- Global Change Biol. 9: 1137-1144.

Végvári, Z., Bókony, V., Barta, Z. and Kovács, G. 2010. Life history predicts advancement of avian spring migration in response to climate change.- Global Change Biol. 16: 1-11.

Verboven, N. and Visser, M.E. 1998. Seasonal variation in local recruitment of great tits: the importance of being early.- Oikos 81: 511-524.

Visser, M.E., Adriaensen, F., van Balen, J.H., Blondel, J., Dhondt, A.A., van Dongen, S., du Feu, C., Ivankina, E.V., Kerimov, A.B., de Laet, J., Matthysen, E., McCleery, R., Orell, M., and Thomson D.L. 2003. Variable responses to large-scale climate change in European Parus populations.- Proc. R. Soc. B 270: 367-372.

Visser, M.E., Perdeck, A.C., Van Balen, J.H. and Both, C. 2009. Climate change leads to decreasing bird migration distances.- Global Change Biol. 15: 1859-1865

van Vliet, J., Musters, C.J.M. and ter Keurs, W.J. 2009. Changes in migration behaviour of Blackbirds Turdus merula from the Netherlands.- Bird Study 56: 276-281.

Willoughby, E.J. and Cade, T.J. 1964. Breeding behavior of the American kestrel (sparrow hawk).- Living Bird 3: 75-96

Zuckerberg, B., Bonter, D.N., Hochachka, W.M., Koenig, W.D., DeGaetano, A.T. and Dickinson, J.L. 2011. Climatic constraints on wintering bird distributions are modified by urbanization and weather.- J. Anim. Ecol. 80: 403-413. 
Table 1. Explanatory variables used to model migration distance $(\ln [\mathrm{km}])$ based on ringing and encounter locations of American kestrels in western North America 1960-2009. Kestrels were ringed in the spring and summer (Apr- 15 Aug) and encountered in the winter (Nov-Feb) or ringed in the winter and encountered in the spring or summer $(n=104)$.

\begin{tabular}{lcccc}
\hline variable & estimate (SE) & d.f. & F & p-value \\
\hline sex (female) & $0.70(0.32)$ & 1,99 & 6.05 & 0.0156 \\
nesting latitude & $0.94(0.17)$ & 1,99 & 22.30 & $<0.0001$ \\
tmin $^{\mathrm{a}}$ & $-0.26(0.16)$ & 1,99 & 7.9 & 0.0057 \\
winter year & $-0.54(0.17)$ & 1,99 & 10.13 & 0.0019 \\
& & & & \\
\hline
\end{tabular}




\section{Figure Legend}

Figure 1. American kestrel migration distance residuals, $\ln (\mathrm{km})$, from a model with sex, nesting latitude, and average daily winter minimum temperature anomaly over time. Migration distances of kestrels ringed and encountered in western North America decreased significantly from 1960 to 2009 .

Figure 2. (a) Average ( $\pm \mathrm{SE}$ ) daily winter (Nov-Feb) minimum temperature anomalies for western United States (1990-2009). Washington, California, Idaho, Utah, and Arizona had significantly warmer minimum temperatures compared to the reference period of 1961-1990. Oregon and Nevada minimum temperature anomalies were not significantly greater than zero. Statistical significance is indicated by asterisks. b-h. Number of American kestrels per 100 observer hours (kestrels_100hr-1) of CBCs from 1960-2009 in the western United States. The CBC index of overwintering populations increased significantly for Washington (b), Idaho (e), and Utah (f), showed no change for Oregon (c) and Nevada (g), and decreased for California (d) and Arizona (h). An increase in northern latitudes and decrease in southern states is consistent with shorter distances between overwintering sites and nesting locations.

Figure 3. Average annual American kestrel nest discovery dates were negatively associated with winter minimum temperature anomalies from 1987-2009, except 2007. Kestrels tended to nest earlier after warmer winters. 


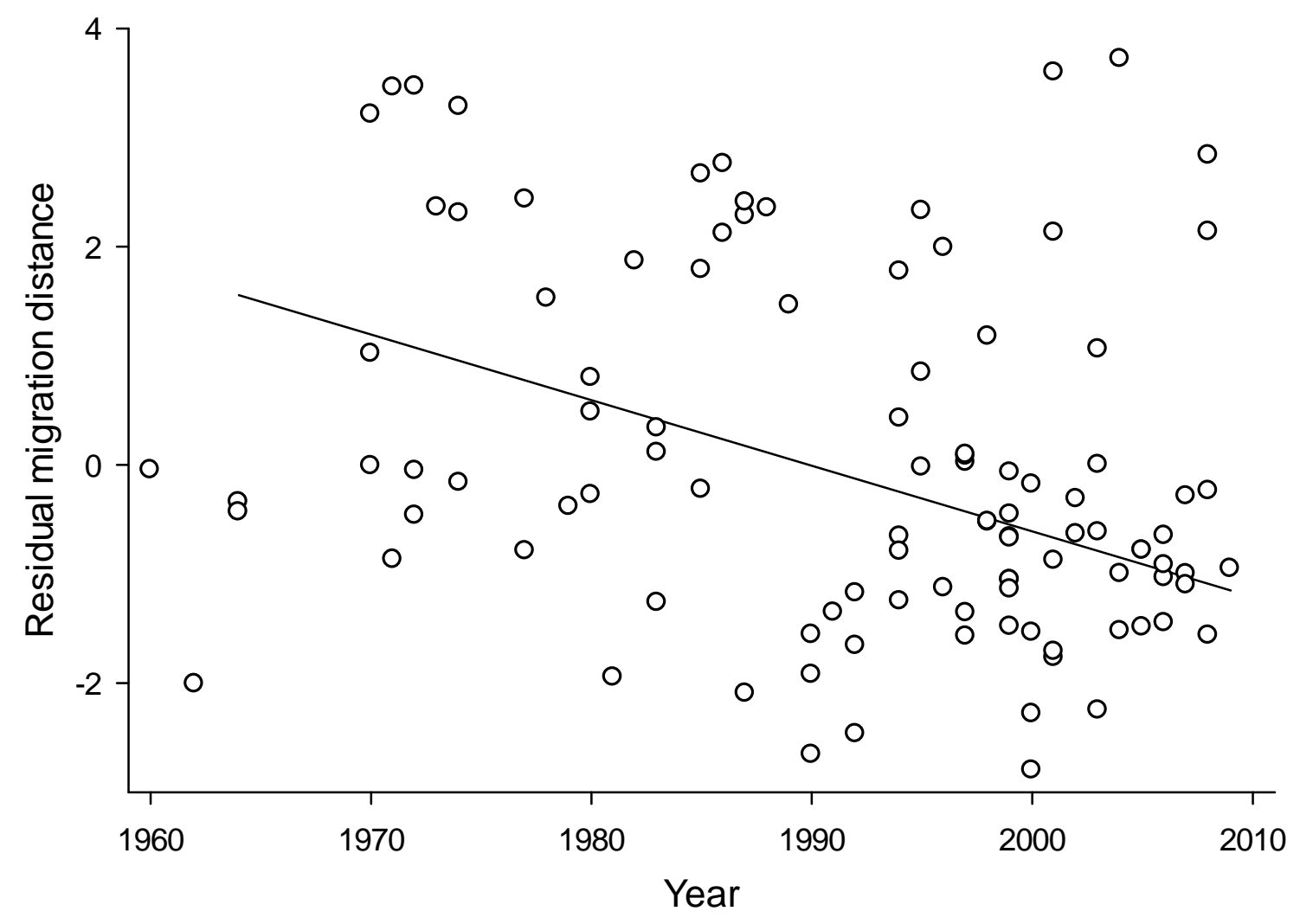

Figure 1. 

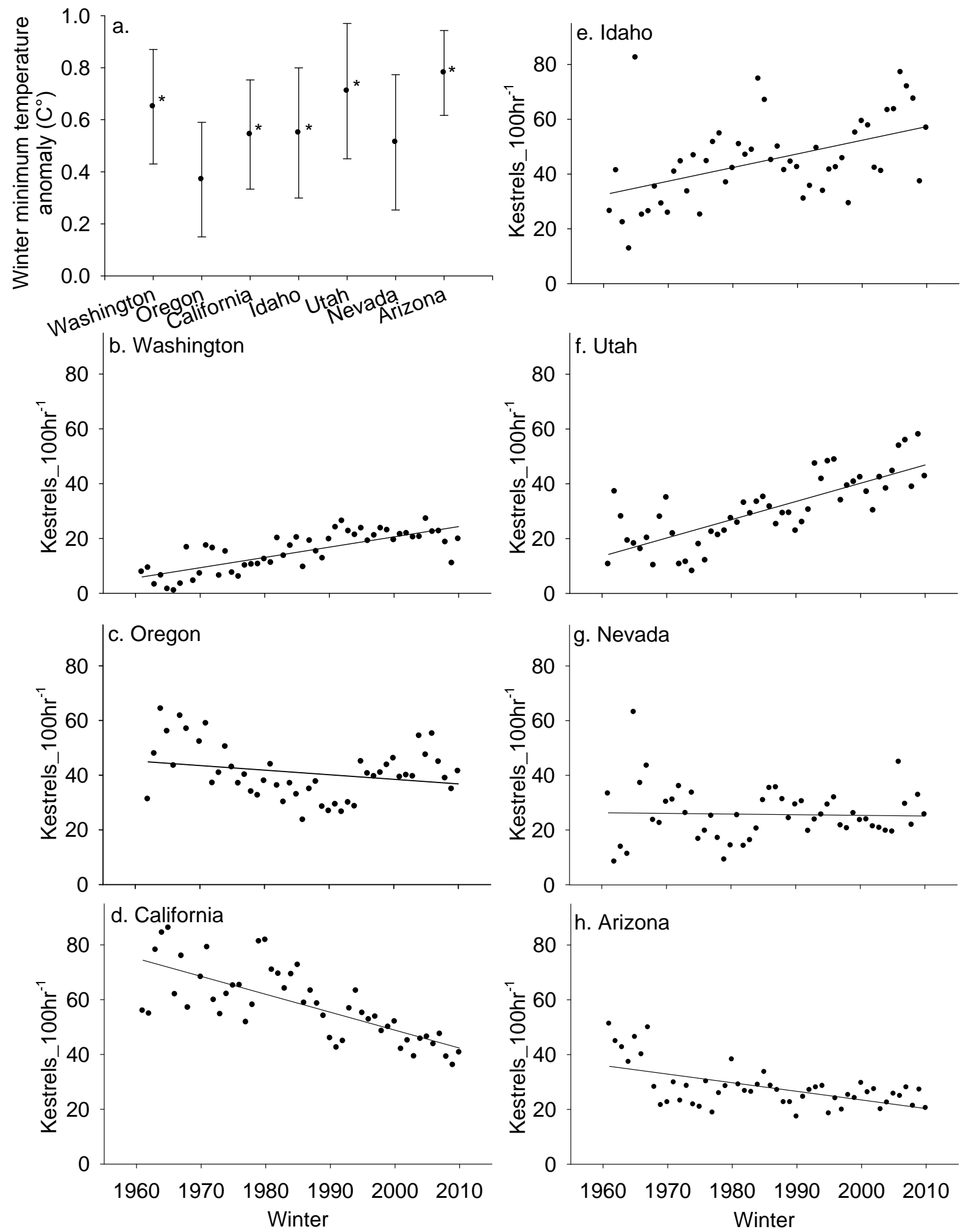

Figure 2. 


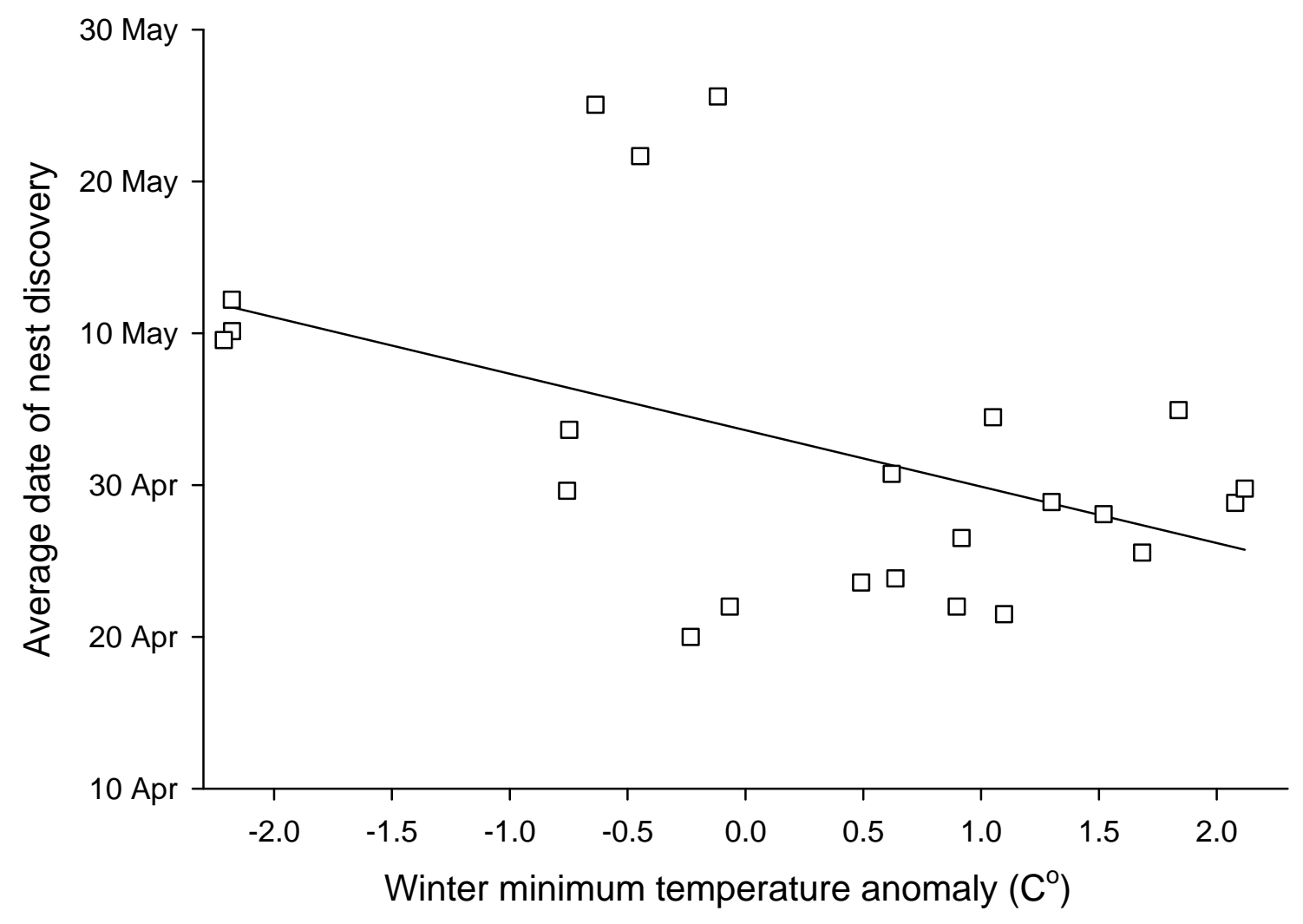

Figure 3. 